\title{
Efficacy of unilateral transverse process-pedicle and bilateral puncture techniques in percutaneous kyphoplasty for Kummell disease
}

\author{
XIAO-MING XIONG ${ }^{1 *}$, YU-LIANG SUN ${ }^{1 *}$, SI-MAO SONG ${ }^{1}$, MAO-YI YANG $^{2}$, \\ $\mathrm{JIE} \mathrm{ZHOU}^{2}$, DUN WAN ${ }^{1}$, XUAN-GENG DENG ${ }^{1}$ and HUA-GANG SHI ${ }^{1}$ \\ ${ }^{1}$ Department of Spinal Surgery, Sichuan Orthopaedic Hospital; ${ }^{2}$ School of Sports Medicine and Health, \\ Chengdu Sports University, Chengdu, Sichuan 610041, P.R. China
}

Received August 14,2018; Accepted April 11, 2019

DOI: $10.3892 /$ etm.2019.7980

\begin{abstract}
In the present study, the efficacy of unilateral transverse process-pedicle and bilateral puncture techniques in percutaneous kyphoplasty (PKP) for Kummell disease was compared. Between March 2015 and June 2017, 63 patients with Kummell disease were recruited and underwent PKP with two different puncture techniques: A total of 38 patients were treated by unilateral transverse process-pedicle PKP and 25 patients were treated by bilateral PKP. The operative time, intra-operative fluoroscopy time, volume of bone cement injection and bone cement leakage were recorded. Prior to surgery and 1 day post-surgery, the visual analogue scale (VAS) pain score and Oswestry disability index (ODI) were determined, and the vertebral body height and Cobb angle were measured. The results indicated that the incidence of bone cement leakage in the unilateral group was similar with the bilateral group $(15.79 \%$ vs. $16.00 \%)$, with no statistically significant difference between the two groups. None of the patients in the two groups had any obvious damage of the spinal cord. The operative time, intra-operative fluoroscopy time and volume of bone cement injection in the unilateral group were lower than those in the bilateral group. A chest X-ray examination at 1 day post-surgery revealed no pulmonary embolism in the two groups. The VAS score, ODI, vertebral body height and Cobb angle were significantly improved in the unilateral and bilateral groups at 1 day post-surgery and at the last follow-up (12 months post-surgery) as compared with these parameters prior to surgery. In conclusion, the unilateral transverse
\end{abstract}

Correspondence to: Dr Xiao-Ming Xiong, Department of Spinal Surgery, Sichuan Orthopaedic Hospital, 132 West Section of The First Ring Road, Wuhou, Chengdu, Sichuan 610041, P.R. China E-mail: xingjia5759191@163.com

*Contributed equally

Keywords: percutaneous kyphoplasty, unilateral, bilateral,Kummell disease process-pedicle and bilateral puncture techniques in PKP exhibited good efficacy as a treatment for Kummell disease. The operative time, intra-operative fluoroscopy time and volume of bone cement injection were lower in the unilateral group.

\section{Introduction}

In 1895, the German surgeon Kummell first reported on six patients with a vertebral body compression fracture after a minor trauma, which led to delayed collapse of the vertebral body. The disease later became known as 'Kummell disease'. The incidence of Kummell disease increases with age and the presence of osteoporosis. Wang et al (1) linked Kummell disease to infarction of the vertebral body, with trauma and osteoporosis being the major factors responsible for the infarction. Li et al (2) divided Kummell disease into three stages (stage I, II and III). In stage I, the vertebral body height loss is $<20 \%$, with or without adjacent intervertebral disc degeneration, whereas the vertebral body height loss in stage II is $>20 \%$ and is usually accompanied by adjacent intervertebral disc degeneration. Stage III Kummell disease is characterized by posterior breakage combined with spinal cord compression (2). Various factors associated with Kummell disease, including neurological deficits, back pain and spinal canal stenosis, may increase the risk of disability and mortality, and reduce the quality of life (3). Thus, the development of a suitable surgical technique for use in Kummell disease is urgently required.

Previous studies have indicated that percutaneous kyphoplasty (PKP) in stage I, II and III Kummell disease achieved a good curative effect $(4,5)$. Compared with bone cement-augmented short segmental fixation, PKP was associated with better early clinical outcomes and reduced blood loss, as well as decreased operative times and duration of stay at the hospital (6). PKP also immediately alleviated vertebral body pain and restored the stiffness and strength of the vertebral body via the use of polymethyl methacrylate (PMMA) cement, which provided stability and support (7). PMMA is the most commonly used cement in PKA, and the use of PMMA with improved viscosity and working times as well as radiofrequency-targeted augmentation and implants, has led to progress in the treatment of Kummell 
disease (7). The bilateral approach, which is relatively safe and effective, is considered the mainstay of PKP for Kummell disease $(8,9)$. Certain studies have proposed that, as compared with bilateral PKP, unilateral PKP may offer a number of benefits, including a shorter operative time, lower complication rate and less radiation exposure $(10,11)$. A comparison of bilateral and unilateral approaches may provide evidence for surgeons in the selection of PKP.

In the present study, the efficacy of the unilateral transverse process-pedicle and bilateral puncture technique in PKP for patients with Kummell disease was retrospectively analyzed.

\section{Materials and methods}

Inclusion and exclusion criteria. The inclusion criteria were patients who met the diagnostic criteria for Kummell disease, without a known history of trauma or acute minor trauma and intractable chest and back pain, which receded upon bed rest and worsened upon sitting and walking, as well as kyphosis and local percussion pain, ineffective conservative treatment for $>3$ months, and imaging revealing a vacuum sign, fissure sign, pseudoarthrosis or fracture sclerosis. Additional inclusion criteria were an age of $>55$ years, a lesional segment of $\mathrm{T}_{11}-\mathrm{L}_{4}$, stage I or II disease and a bone density T-value of $<-2.5$ on dual-energy X-ray absorptiometry, which is in accordance with the diagnostic criteria for osteoporosis (12).

The exclusion criteria were combined serious internal medical diseases, a fresh fracture, or a pathological fracture associated with a metastatic tumor or primary tumor of the vertebral body.

Patients. A total of 63 patients with Kummell disease who met the diagnostic criteria and underwent PKP between March 2015 and June 2017 with one of the two puncture techniques were recruited (registration number 2015-3-31-1). Due to the increased cost of bilateral surgery, certain patients selected the unilateral method, which is cheaper and theoretically safe. A total of 38 patients were treated with the unilateral method and 25 patients were treated with the bilateral method. In the unilateral group, there were 7 males and 31 females aged 57-81 years, with an average age of 69.7 years. The course of the disease was between 16 and 44 weeks, with an average duration of 19.5 weeks. The lesional segment was classified as $\mathrm{T}_{11}, \mathrm{~T}_{12}, \mathrm{~L}_{1}, \mathrm{~L}_{2}$ and $\mathrm{L}_{3}$ in $3,9,14,7$ and 5 patients, respectively. A total of 12 patients had stage I disease and 28 patients had stage II disease. The bone density T-value was between -3.9 and -2.5 , with an average T-value of -2.9 . In the bilateral group, there were 6 males and 19 females aged 56-84 years, with an average age of 69.4 years. The course of the disease was between 14 and 51 weeks, with an average duration of 18.4 weeks. The lesional segment was classified as $\mathrm{T}_{11}, \mathrm{~T}_{12}, \mathrm{~L}_{1}$, $\mathrm{L}_{2}, \mathrm{~L}_{3}$ and $\mathrm{L}_{4}$ in 2, 9, 8, 2, 2 and 2 patients, respectively. A total of 8 patients had stage I disease and 17 patients had stage II disease. The bone density T-value was between -3.7 to -2.6 , with an average T-value of -2.9.

Frontal and lateral chest X-ray, computed tomography in cases of injured vertebrae and chest magnetic resonance imaging were performed prior to surgery. There were no significant inter-group differences in terms of sex, age, course of disease, lesional segment, bone density T-value, pre-operative visual analog scale (VAS) pain score, Oswestry disability index (ODI), vertebral body height and Cobb angle (13) (Table I).

Surgical techniques. Surgery was performed in accordance with a previous report with some modifications as listed below (14). Under general anesthesia, the patient was placed in the prone position during the X-ray examination. The C-arm was adjusted to ensure that there was no bilateral shadow on the affected vertebral body and the puncture entry point was marked (3-o'clock on the right side and 9-o'clock on the left side). When the puncture point reached the anterior one-third of the posterior margin of the vertebral body, a working tunnel was established using a needle, dilated duct and working casing pipe. In the present study, a balloon was then guided into the anterior one-third of the affected vertebral body. A pressure injection device was connected to the balloon and iohexol was injected to monitor the balloon expansion. When the pressure reached $350 \mathrm{kPa}$, a core needle in the balloon was extracted from the balloon to expand to locations affected by osteoporosis. In the unilateral group, prior to injection of the PMMA bone cement, the fluid and air in the vertebral body were exhausted, and the bone cement was injected, as described previously. In the bilateral group, a puncture entry point was made on the other side. A tunnel was established and the vertebral body was expanded through the working tunnel. After vertebral body reduction, the bone cement was injected into the vertebral body. When the bone cement had diffused into the posterior one-third of the vertebral body, the bone cement volume was reduced and the fluoroscopy time was increased. Once bone cement leakage was detected or the bone cement filled the cavity, the bone cement injection was stopped and the puncture needle was removed. The wound was then covered by a sterile wound dressing. Post-operative electrocardiograph monitoring was performed for $2 \mathrm{~h}$. All of the patients were fitted with a corset and regained remobilization at 1 day after the operation.

Evaluation indices. The operative time, intra-operative fluoroscopy time, volume of bone cement material and bone cement leakage were recorded.

The VAS was used to assess the pain scores of the patients prior to surgery, at 1 and 3 days post-surgery, and at 1, 6 and 12 months post-surgery. A 10-cm-long line, with 'painless (score $=0$ )' and 'severe pain (score $=10$ )' marked at either end, was used. According to the degree of pain, the patients marked a point on the line to indicate the intensity and psychological impact of the pain. The numeric value of the distance from the starting point to the marked point in $\mathrm{cm}$ resembled the VAS score. The higher the score, the more severe the pain was considered to be.

The ODI was used to assess the ability of the patients to pursue daily activities of life prior to surgery, at 1 and 3 days post-surgery, and at 1, 6 and 12 months post-surgery. The ODI includes an assessment of pain (the degree of pain and the effect of pain on sleep), single functions (lying down, sitting, standing and walking) and comprehensive function (activities of daily living, sexual life and social activities). Each item was scored as $0-5$ points. The corresponding scores of the answers to 10 items were accumulated and the ODI was calculated as the percentage of the accumulated score $/ 50$ points. The higher the score, the more severe the level of dysfunction was considered to be. 
Table I. Comparison of operation indices between the two groups.

\begin{tabular}{lcccc}
\hline Group & $\mathrm{n}$ & Operation time $(\mathrm{min})$ & $\begin{array}{c}\text { Intra-operative fluoroscopy } \\
\text { times (number of repeats) }\end{array}$ & $\begin{array}{c}\text { Volume of bone } \\
\text { cement injection (ml) }\end{array}$ \\
\hline Unilateral & 38 & $36.54 \pm 10.23$ & $17.98 \pm 2.58$ & $4.62 \pm 1.03$ \\
Bilateral & 25 & $50.26 \pm 12.06$ & $20.16 \pm 3.02$ & $5.57 \pm 1.08$ \\
Statistics & & $\mathrm{t}=-4.253$ & $\mathrm{t}=-3.019$ & $\mathrm{t}=-3.275$ \\
& $\mathrm{P}<0.001$ & $\mathrm{P}=0.005$ & $\mathrm{P}=0.003$ \\
\hline
\end{tabular}

Values are expressed as the mean \pm standard deviation.



Figure 1. Representative case of a 67-year-old male patient with Kummell disease at $\mathrm{T}_{12}$ from the unilateral group. (A and B) Pre-operative X-ray images in (A) frontal and (B) lateral view. (C) Pre-operative CT. (D) Pre-operative magnetic resonance image. (E and F) X-ray images at 1 day post-surgery in the (E) frontal and (F) lateral view revealed evenly distributed bone cement and restoration of the vertebral body height, with little bone cement leakage in the vertebral endplate. (G) CT at 1 day post-surgery indicated little bone cement leakage in the anterior vertebral body. (H and I) X-ray images 12 months post-surgery in (H) frontal and (I) lateral view. CT, computed tomography.

The vertebral body height was used to assess the recovery of the vertebral body. The method of Pflugmacher (15) was used to measure the distance between the upper and lower endplates of the anterior vertebral body prior to surgery, at 1 and 3 days post-surgery, and at 1, 6 and 12 months post-surgery.

The Cobb angle was used to assess the recovery of the vertebral body. Phillips's method (16) was used to measure the angle of the intersection of the vertical line of the upper vertebral endplate and lower vertebral endplate of injured vertebrae prior to surgery, at 1 and 3 days post-surgery, and at 1, 6 and 12 months post-surgery.

Statistical analysis. SPSS software, version 17 (SPSS Inc., Chicago, IL, USA) was used for all the statistical analyses. 


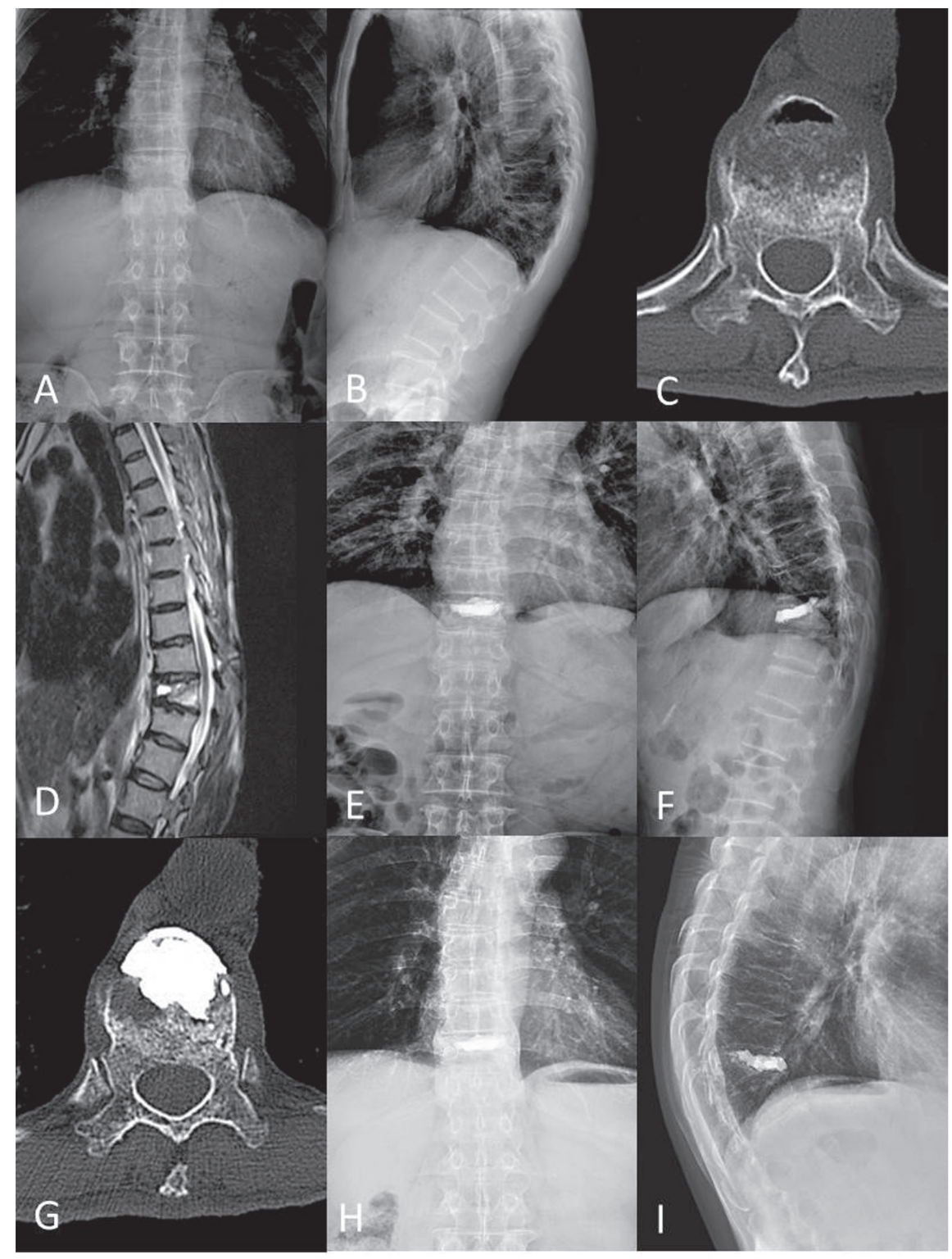

Figure 2. Representative case of a 66-year-old female patient with Kummell disease at $T_{11}$ from the unilateral group. (A and B) Pre-operative X-ray images in (A) frontal and (B) lateral view. (C) Pre-operative CT. (D) Pre-operative magnetic resonance image. (E and F) X-ray images at 1 day post-surgery in the (E) frontal and (F) lateral view indicated little bone cement leakage in the vertebral endplate. (G) CT at 1 day post-surgery indicated little bone cement leakage in the anterior vertebral body. (H and I) X-ray images 14 months post-surgery in (H) frontal and (I) lateral view. CT, computed tomography.

Values are expressed as the mean \pm standard deviation. A comparative analysis between the groups was performed using an independent two-samples t-test. Repeated-measures analysis of variance was used to compare different assessments in each group, followed by a Newman-Keuls post-hoc test. Categorical variables were compared using the $\chi^{2}$ test. $\mathrm{P}<0.05$ was considered to indicate statistical significance.

\section{Results}

Clinical outcomes. Various operation indices for the two groups are provided in Table I. In the unilateral group, there were six cases of bone cement leakage (15.79\%) and the leakage reached the anterior vertebrae in all cases. In the bilateral group, there were four cases of bone cement leakage (16.00\%), with the leakage reaching the anterior vertebrae in one case and the intervertebral disc in three cases. There was no statistically significant inter-group difference in the incidence of bone cement leakage $\left(\chi^{2}=<0.001 ; \mathrm{P}<0.001\right)$. The operative time, intra-operative fluoroscopy time and volume of bone cement injection in the unilateral group were significantly lower than those in the bilateral group $(\mathrm{P}<0.05)$. The chest $\mathrm{X}$-ray examination exhibited no pulmonary embolism at 1 day post-surgery in the two groups. There were no complications, including re-fracture of the vertebral body or displacement of bone cement block, in either group, as exemplified by representative cases, whose images are provided in Figs. 1 and 2.

Comparison of indices in the follow-up period. The duration of follow-up was between 12 and 24 months for all of the patients, with an average period of 16.4 months. There were no significant differences in the VAS scores between the unilateral and bilateral groups ( $P>0.05)$, although the VAS score in the bilateral group was lower than that in the unilateral group (Table II). The 
Table II. Comparison of visual analog scale score between the two groups at different time-points.

Following surgery

\begin{tabular}{lccccccc}
\cline { 4 - 7 } Group & $\mathrm{N}$ & Prior to surgery & 1 day & 3 days & 1 month & 6 months & 12 months \\
\hline Unilateral & 38 & $6.73 \pm 1.00$ & $3.50 \pm 0.91^{\mathrm{a}}$ & $3.12 \pm 0.87^{\mathrm{a}, \mathrm{b}}$ & $2.35 \pm 0.94^{\mathrm{a}, \mathrm{b}}$ & $1.70 \pm 0.85^{\mathrm{a}, \mathrm{b}}$ & $1.38 \pm 0.82^{\mathrm{a}, \mathrm{b}}$ \\
Bilateral & 25 & $6.37 \pm 0.96$ & $3.42 \pm 1.07^{\mathrm{a}}$ & $3.08 \pm 0.93^{\mathrm{a}, \mathrm{b}}$ & $2.31 \pm 0.98^{\mathrm{a}, \mathrm{b}}$ & $1.65 \pm 0.79^{\mathrm{a}, \mathrm{b}}$ & $1.32 \pm 0.75^{\mathrm{a}, \mathrm{b}}$ \\
Statistics & & $\mathrm{t}=1.213$ & $\mathrm{t}=0.270$ & $\mathrm{t}=0.148$ & $\mathrm{t}=0.138$ & $\mathrm{t}=0.201$ & $\mathrm{t}=0.251$ \\
& & $\mathrm{P}=0.232$ & $\mathrm{P}=0.788$ & $\mathrm{P}=0.883$ & $\mathrm{P}=0.891$ & $\mathrm{P}=0.842$ & $\mathrm{P}=0.803$ \\
\hline
\end{tabular}

${ }^{\text {a }} \mathrm{P}<0.05$ vs. prior to surgery; ${ }^{\mathrm{b}} \mathrm{P}<0.05$ vs. one day post-surgery. Values are expressed as the mean \pm standard deviation.

Table III. Comparison of Oswestry disability index between the two groups at different time-points.

\begin{tabular}{|c|c|c|c|c|c|c|c|}
\hline \multirow[b]{2}{*}{ Group } & \multirow[b]{2}{*}{$\mathrm{N}$} & \multirow[b]{2}{*}{ Prior to surgery } & \multicolumn{5}{|c|}{ Following surgery } \\
\hline & & & 1 day & 3 days & 1 month & 6 months & 12 months \\
\hline Unilateral & 38 & $68.00 \pm 6.70$ & $32.73 \pm 5.05^{\mathrm{a}}$ & $28.54 \pm 5.78^{\mathrm{a}, \mathrm{b}}$ & $22.78 \pm 5.47^{\mathrm{a}, \mathrm{b}}$ & $18.84 \pm 5.05^{\mathrm{a}, \mathrm{b}}$ & $15.34 \pm 4.14^{\mathrm{a}, \mathrm{b}}$ \\
\hline Bilateral & 25 & $68.16 \pm 7.67$ & $33.74 \pm 7.05^{\mathrm{a}}$ & $29.23 \pm 6.64^{\mathrm{a}, \mathrm{b}}$ & $23.28 \pm 5.75^{\mathrm{a}, \mathrm{b}}$ & $18.25 \pm 5.36^{\mathrm{a}, \mathrm{b}}$ & $14.62 \pm 4.36^{\mathrm{a}, \mathrm{b}}$ \\
\hline \multirow[t]{2}{*}{ Statistics } & & $\mathrm{t}=0.074$ & $\mathrm{t}=0.561$ & $\mathrm{t}=0.371$ & $\mathrm{t}=0.296$ & $\mathrm{t}=0.377$ & $t=0.563$ \\
\hline & & $\mathrm{P}=0.941$ & $\mathrm{P}=0.578$ & $\mathrm{P}=0.712$ & $\mathrm{P}=0.769$ & $\mathrm{P}=0.708$ & $\mathrm{P}=0.576$ \\
\hline
\end{tabular}

${ }^{\mathrm{a}} \mathrm{P}<0.05$ vs. prior to surgery; ${ }^{\mathrm{P}}<0.05$ vs. one day post-surgery. Values are expressed as the mean \pm standard deviation.

VAS scores were significantly decreased in the unilateral and bilateral groups at 1 day post-surgery as compared with those pre-surgery (Table II). With the increase in the follow-up time, the VAS scores of the two groups gradually decreased, and there was a statistically significant difference in the scores between the first day post-surgery and the later time-points $(\mathrm{P}<0.05)$.

There were no significant inter-group differences in the ODI scores $(\mathrm{P}>0.05)$, although the ODI scores of the bilateral group were higher than those of the unilateral group (Table III). In each of the two groups, the ODI scores had decreased significantly at 1 day post-surgery as compared with those prior to surgery (Table III). With the increase in the follow-up time, the ODI scores of the two groups gradually decreased, and there was a statistically significant difference between the scores at day 1 post-surgery and the later time-points $(\mathrm{P}<0.05)$.

As presented in Table IV, there were no significant inter-group differences in the vertebral body height $(\mathrm{P}>0.05)$. In either of the two groups, the vertebral body height was significantly increased at 1 day post-surgery as compared with that prior to surgery $(\mathrm{P}<0.05)$.

There were no significant differences in the Cobb angles of the unilateral and bilateral groups $(\mathrm{P}>0.05)$, as indicated in Table V. In the unilateral and bilateral groups, the Cobb angle was significantly decreased at 1 day post-surgery as compared with that prior to surgery $(\mathrm{P}<0.05$; Table $\mathrm{V})$.

\section{Discussion}

Kummell disease is a complication of osteoporosis, osteogenesis decline, intervertebral disc degeneration, microfractures, fatigue fractures, inadequate blood flow and pseudoarthrosis (17); it is caused by vertebral body infarction, with trauma and osteoporosis thought to be the major factors responsible for the infarction (1). Usually, Kummell disease is diagnosed based on an intravertebral vacuum cleft sign (18). The affected vertebral body exhibits marked mobility, with a decreased height, which increases during hyperextension. There are no neurological symptoms in stage I and II Kummell disease. Thus, at these stages, the major aim is to eliminate the mobility of the fractured vertebrae and restore spinal stability (15). By contrast, stage III disease is characterized by rupture of the posterior vertebral wall, together with severe kyphosis and neurospinal symptoms, for which open surgery is recommended (19).

As a treatment for Kummell disease, PKP may immediately alleviate pain and restore the stiffness and strength of the vertebral body through the stability and support provided by PMMA (20). Kim et al (21) reported that a bone cement volume of $30 \%$ of the vertebral body volume restored the level of stiffness to that of normal bone. However, if the bone cement volume exceeded $30 \%$ of the vertebral body volume, the stiffness exceeded that of normal bone. Thus, an appropriate bone cement volume is vital for restoration of the vertebral body. In the present study, although the volume of bone cement in the unilateral group was significantly lower than that in the bilateral group, a unilateral puncture may result in an uneven distribution of bone cement in the vertebral body, unilateral weight bearing, lateral compression and collapse of the non-operative side of the vertebral body $(22,23)$.

In a previous biomechanical analysis, unipedicular kyphoplasty and bipedicular kyphoplasty restored the 
Table IV. Comparison of vertebral body height between the two groups at different time-points.

Following surgery

\begin{tabular}{|c|c|c|c|c|c|c|c|}
\hline Group & $\mathrm{N}$ & Prior to surgery & 1 day & 3 days & 1 month & 6 months & 12 months \\
\hline Unilateral & 38 & $16.08 \pm 1.96$ & $20.62 \pm 1.64^{\mathrm{a}}$ & $20.62 \pm 1.62^{\mathrm{a}, \mathrm{b}}$ & $20.60 \pm 1.64^{\mathrm{a}, \mathrm{b}}$ & $20.58 \pm 1.60^{\mathrm{a}, \mathrm{b}}$ & $20.56 \pm 1.57^{\mathrm{a}, \mathrm{b}}$ \\
\hline Bilateral & 25 & $15.61 \pm 1.24$ & $20.04 \pm 1.21^{\mathrm{a}}$ & $20.04 \pm 1.24^{\mathrm{a}, \mathrm{b}}$ & $20.02 \pm 1.20^{\mathrm{a}, \mathrm{b}}$ & $20.00 \pm 1.25^{\mathrm{a}, \mathrm{b}}$ & $20.00 \pm 1.16^{\mathrm{a}, \mathrm{b}}$ \\
\hline \multirow[t]{2}{*}{ Statistics } & & $\mathrm{t}=0.983$ & $\mathrm{t}=1.303$ & $\mathrm{t}=1.305$ & $\mathrm{t}=1.306$ & $\mathrm{t}=1.313$ & $\mathrm{t}=1.313$ \\
\hline & & $\mathrm{P}=0.331$ & $\mathrm{P}=0.199$ & $\mathrm{P}=0.199$ & $\mathrm{P}=0.198$ & $\mathrm{P}=0.196$ & $\mathrm{P}=0.196$ \\
\hline
\end{tabular}

${ }^{\text {a }} \mathrm{P}<0.05$ vs. prior to surgery; ${ }^{\mathrm{b}} \mathrm{P}<0.05$ vs. one day post-surgery. Values are expressed as the mean \pm standard deviation.

Table V. Comparison of Cobb angle between the two groups at different time-points.

Following surgery

\begin{tabular}{|c|c|c|c|c|c|c|c|}
\hline Group & $\mathrm{N}$ & Prior to surgery & 1 day & 3 days & 1 month & 6 months & 12 months \\
\hline Unilateral & 38 & $14.53 \pm 3.96$ & $8.66 \pm 2.51^{\mathrm{a}}$ & $8.66 \pm 2.54^{\mathrm{a}, \mathrm{b}}$ & $8.66 \pm 2.48^{a, b}$ & $8.67 \pm 2.52^{\mathrm{a}, \mathrm{b}}$ & $8.69 \pm 2.57^{\mathrm{a}, \mathrm{b}}$ \\
\hline Bilateral & 25 & $14.93 \pm 3.66$ & $8.46 \pm 2.66^{\mathrm{a}}$ & $8.46 \pm 2.65^{\mathrm{a}, \mathrm{b}}$ & $8.46 \pm 2.63^{\mathrm{a}, \mathrm{b}}$ & $8.48 \pm 2.62^{\mathrm{a}, \mathrm{b}}$ & $8.51 \pm 2.68^{\mathrm{a}, \mathrm{b}}$ \\
\hline Statistics & & $\mathrm{t}=0.345$ & $\mathrm{t}=0.257$ & $\mathrm{t}=0.256$ & $\mathrm{t}=0.260$ & $\mathrm{t}=0.246$ & $\mathrm{t}=0.228$ \\
\hline & & $\mathrm{P}=0.732$ & $\mathrm{P}=0.798$ & $\mathrm{P}=0.799$ & $\mathrm{P}=0.796$ & $\mathrm{P}=0.807$ & $\mathrm{P}=0.821$ \\
\hline
\end{tabular}

${ }^{\mathrm{a}} \mathrm{P}<0.05$ vs. prior to surgery; ${ }^{\mathrm{b}} \mathrm{P}<0.05$ vs. one day post-surgery. Values are expressed as the mean \pm standard deviation.

strength and stiffness of the vertebral body, and unipedicular kyphoplasty did not increase the risk of lateral compression based on a comparison of the vertebral body height (5). The present results indicated that the operative time, intra-operative fluoroscopy time and volume of bone cement injection in the unilateral group were significantly lower than those in the bilateral group, indicating that unilateral PKP was beneficial in decreasing the operative time, $\mathrm{X}$-ray radiation dose and the puncture wound size. In the follow-up period, none of the patients experienced refracture around the vertebral body, suggesting that the unilateral puncture method was able to restore the strength and stiffness of the affected vertebral body. Studies by Yan et al $(24,14)$ reported that pain and the kyphotic angle were reduced in their unilateral and bilateral groups, whereas the volume of the injected cement and radiation dose in the unilateral group were lower than those in the bilateral group. Hence, the current study demonstrated that unilateral PKP had a similar curative effect as bilateral PKP, and the radiation dose, operative time and complication rate were all lower than those in the bilateral PKP group, which was consistent with the results of previous studies (13)

In the unilateral puncture approach, the inclined angle of the puncture is increased to distribute the bone cement to the opposite side, which increases puncture-associated risks. To address these issues, the balloon must be placed in the anterior one-third of the vertebral body to allow the bone cement to diffuse into the midline and contralateral vertebral body (25). The balloon may be extended and expanded twice during surgery, which aids in the recovery of the vertebral body height. To avoid rupture of the vertebral body wall and balloon and the risk of bone cement leakage, the pressure achieved by balloon dilatation should not be excessively high (26). In certain patients with acute fractures, the vertebral body contains a large amount of fluid. In such cases, prior to bone cement injection, the fluid in the vertebral body should be removed to reduce the injection pressure and facilitate bone cement diffusion and anchorage of the bone cement to the vertebral wall (26).

Of note, the present study has certain limitations. The number of patients with Kummell disease was relatively small, and the length of the follow-up period was not sufficient. In the present study, spinal cord damage, operative time and intra-operative fluoroscopy time, as well as the volume of bone cement injection, were lower in the unilateral group than those in the bilateral group, and the VAS scores, ODI scores, vertebral body height and Cobb angle were measured during the follow-up period to indicate the curative effect between uni- and bilateral groups. A study with a larger patient population (200 or more patients) and a longer follow-up period ( 24 months post-surgery) will be performed in the future.

In conclusion, the present study indicated that bilateral and unilateral PKP are able to efficiently relieve pain, restore the vertebral body height, reduce the Cobb angle and restore spinal stability. As compared with bilateral PKP, unilateral PKP was associated with shorter operative times and intraoperative fluoroscopy times. However, as indicated by previous studies, the risk of unevenly distributed bone cement with unilateral PKP may be higher than that with bilateral PKP. Therefore, unilateral PKP may be a priority on the basis of proficiency in PKP. 


\section{Acknowledgements}

Not applicable.

\section{Funding}

No funding received.

\section{Availability of data and materials}

The datasets used during the present study are available from the corresponding author on reasonable request.

\section{Authors' contributions}

$\mathrm{XX}$ and $\mathrm{YS}$ conceived and designed the current study, prepared the manuscript and performed statistical analysis. SS and MY acquired the data. JZ and DW contributed to the quality control of data and algorithms. XD and HS analyzed and interpreted the data. All authors read and approved the final version of the manuscript.

\section{Ethical approval and consent to participate}

The study was approved by the ethics committee of Sichuan Orthopaedic Hospital (Sichuan, China) and informed consent was obtained from all patients.

\section{Patient consent for publication}

Not applicable.

\section{Competing interests}

The authors declare that they have no competing interests.

\section{References}

1. Wang G, Yang H, Meng B, Zhu X, Zou J, Gan M, Mei X, Chen K and Tang T: Post-traumatic osteoporotic vertebral osteonecrosis treated using balloon kyphoplasty. J Clin Neurosci 18: 664-668, 2011.

2. Li K, Wong T, Kung F, Li A and Hsieh C: Staging of Kümmell's disease. J Musculoskelet Res 8: 43-55, 2004.

3. Zhang X, Hu W, Yu J, Wang Z and Wang Y: An effective treatment option for Kümmell disease with neurological deficits: Modified transpedicular subtraction and disc osteotomy combined with long-segment fixation. Spine (Phila Pa 1976) 41 E923-E930, 2016.

4. Huang Y, Peng M, He S, Tang X, Dai M and Tang C: Clinical efficacy of percutaneous kyphoplasty at the hyperextension position for the treatment of osteoporotic kümmell disease. Clin Spine Surg 29: 161-166, 2016.

5. Chen B, Li Y, Xie D, Yang X and Zheng Z: Comparison of unipedicular and bipedicular kyphoplasty on the stiffness and biomechanical balance of compression fractured vertebrae. Eur Spine J 20: 1272-1280, 2011.

6. Huang YS, Hao DJ, Feng H, Zhang HP, He SM, Ge CY and Niu XB: Comparison of percutaneous kyphoplasty and bone cement-augmented short-segment pedicle screw fixation for management of kümmell disease. Med Sci Monit 24: 1072-1079, 2018.
7. Filippiadis DK, Marcia S, Masala S, Deschamps F and Kelekis A: Percutaneous vertebroplasty and kyphoplasty: Current status, new developments and old controversies. Cardiovasc Intervent Radiol 40: 1815-1823, 2017.

8. Garfin SR, Yuan HA and Reiley MA: New technologies in spine: Kyphoplasty and vertebroplasty for the treatment of painful osteoporotic compression fractures. Spine (Phila Pa 1976) 26: 1511-1515, 2001.

9. Lieberman IH, Dudeney S, Reinhardt MK and Bell G: Initial outcome and efficacy of 'kyphoplasty' in the treatment of painful osteoporotic vertebral compression fractures. Spine (Phila Pa 1976) 26: 1631-1638, 2001.

10. Huang Z, Wan S, Ning L and Han S: Is unilateral kyphoplasty as effective and safe as bilateral kyphoplasties for osteoporotic vertebral compression fractures? A meta-analysis. Clin Orthop Relat Res 472: 2833-2842, 2014.

11. Feng $\mathrm{H}$, Huang $\mathrm{P}$, Zhang $\mathrm{X}$, Zheng $\mathrm{G}$ and Wang Y: Unilateral versus bilateral percutaneous kyphoplasty for osteoporotic vertebral compression fractures: A systematic review and meta-analysis of RCTs. J Orthop Res 33: 1713-1723, 2015.

12. Sun Z, Qiu G and Zhao Y: Application and research advances of metabolomics in the field of orthopedics. Zhonghua Wai Ke Za Zhi 53: 476-480, 2015 (In Chinese).

13. Chang X, Lv YF, Chen B, Li HY, Han XB, Yang K, Zhang W, Zhou Y and Li CQ: Vertebroplasty versus kyphoplasty in osteoporotic vertebral compression fracture: A meta-analysis of prospective comparative studies. Int Orthop 39: 491-500, 2015.

14. Yan L,He B, GuoH,Liu Tand Hao D: The prospective self-controlled study of unilateral transverse process-pedicle and bilateral puncture techniques in percutaneous kyphoplasty. Osteoporos Int 27: 1849-1855, 2016.

15. Pflugmacher R, Schroeder RJ and Klostermann CK: Incidence of adjacent vertebral fractures in patients treated with balloon kyphoplasty: Two years' prospective follow-up. Acta Radiol 47: 830-840, 2006

16. Phillips FM, Isaacs RE, Rodgers WB, Khajavi K, Tohmeh AG, Deviren V, Peterson MD, Hyde J and Kurd M: Adult degenerative scoliosis treated with XLIF: Clinical and radiographical results of a prospective multicenter study with 24-month follow-up. Spine (Phila Pa 1976) 38: 1853-1861, 2013.

17. Kim YC, Kim YH and Ha KY: Pathomechanism of intravertebral clefts in osteoporotic compression fractures of the spine. Spine J 14: 659-666, 2014

18. Wu AM, Chi YL and Ni WF: Vertebral compression fracture with intravertebral vacuum cleft sign: Pathogenesis, image, and surgical intervention. Asian Spine J 7: 148-155, 2013.

19. Li H, Liang CZ and Chen QX: Kümmell's disease, an uncommon and complicated spinal disorder: A review. J Int Med Res 40: 406-414, 2012.

20. Chen GD, Lu Q, Wang GL, Zou J, Yang HL, Yang Y and Luo ZP: Percutaneous kyphoplasty for kummell disease with severe spinal canal stenosis. Pain Physician 18: 1021-1028, 2015.

21. Kim JM, Shin DA, Byun DH, Kim HS, Kim S and Kim HI: Effect of bone cement volume and stiffness on occurrences of adjacent vertebral fractures after vertebroplasty. J Korean Neurosurg Soc 52: 435-440, 2012.

22. Hu M, Ma H, Shi H, Liang Y, Zeng Y and Wang J: Early clinical outcome of manual reduction combined with uni-lateral percutaneous kyphoplasty to treat osteoporotic vertebral compression fracture. Zhongguo Xiu Fu Chong Jian Wai Ke Za Zhi 24: 1092-1096, 2010 (In Chinese).

23. Deng XQ, Wu YS and Wang HM: Application of contralateral supplementary puncture in unilateral percutaneous vertebroplasty for poor bone cement dispersion. Zhongguo Gu Shang 31: 1168-1171, 2018 (In Chinese).

24. Yan L, Jiang R, He B, Liu T and Hao D: A comparison between unilateral transverse process-pedicle and bilateral puncture techniques in percutaneous kyphoplasty. Spine (Phila Pa 1976) 39: B19-B26, 2014.

25. Dalton BE, Kohm AC, Miller LE, Block JE and Poser RD: Radiofrequency-targeted vertebral augmentation versus traditional balloon kyphoplasty: Radiographic and morphologic outcomes of an ex vivo biomechanical pilot study. Clin Interv Aging 7: 525-531, 2012.

26. Guo J, Ding W, Shen Y, Li B, Wu H, Cao L and Li P: Selective treatment of aged osteoporosis thoracolumbar vertebrae burst fracture with balloon kyphoplasty. Zhongguo Xiu Fu Chong Jian Wai Ke Za Zhi 24: 1341-1344, 2010 (In Chinese). 